University of Nebraska - Lincoln

DigitalCommons@University of Nebraska - Lincoln

\title{
Computation of a Face Attractiveness Index Based on Neoclassical Canons, Symmetry, and Golden Ratios
}

\author{
Kendra Schmid \\ University of Nebraska Medical Center, kkschmid@unmc.edu \\ David Marx \\ University of Nebraska-Lincoln, david.marx@unl.edu \\ Ashok Samal \\ University of Nebraska-Lincoln, asamal1@unl.edu
}

Follow this and additional works at: https://digitalcommons.unl.edu/csearticles

Part of the Computer Sciences Commons

Schmid, Kendra; Marx, David; and Samal, Ashok, "Computation of a Face Attractiveness Index Based on Neoclassical Canons, Symmetry, and Golden Ratios" (2008). CSE Journal Articles. 92.

https://digitalcommons.unl.edu/csearticles/92

This Article is brought to you for free and open access by the Computer Science and Engineering, Department of at DigitalCommons@University of Nebraska - Lincoln. It has been accepted for inclusion in CSE Journal Articles by an authorized administrator of DigitalCommons@University of Nebraska - Lincoln. 


\title{
Computation of a Face Attractiveness Index Based on Neoclassical Canons, Symmetry, and Golden Ratios
}

\author{
Kendra Schmid, ${ }^{1}$ David Marx, ${ }^{2}$ Ashok Samal ${ }^{3}$ \\ 1. Department of Biostatistics, University of Nebraska Medical Center, Omaha, NE, USA (kkschmid@unmc.edu) \\ 2. Department of Statistics, University of Nebraska-Lincoln, Lincoln, NE, USA \\ 3. Department of Computer Science and Engineering, University of Nebraska-Lincoln, Lincoln, NE, USA
}

\begin{abstract}
Analysis of attractiveness of faces has long been a topic of research. Literature has identified many different factors that can be related to attractiveness. In this research we analyze the role of symmetry, neoclassical canons, and golden ratio in the determination of attractiveness of a face. We focus on the geometry of a face and use actual faces for our analysis. We find there are some differences in the criteria used by males and females to determine attractiveness. The model we have developed to predict the attractiveness of a face using its geometry is accurate with low residual errors.
\end{abstract}

Keywords: Face attractiveness, Face recognition, Neoclassical canons, Face symmetry, Golden ratio.

\section{Introduction}

A popular axiom concerning physical attractiveness is: "Beauty is in the eye of the beholder." Research in the area of facial perception has identified many different factors that contribute to a face being considered attractive. Armstrong [1] suggests that beauty cannot be defined by one single principle. Rhodes [2] focuses on averageness, symmetry, and sexual dimorphism and their link to facial attractiveness. Little et al.[3] suggest that self-perceived attractiveness influences one's opinion of the attractiveness of others, and DeBruine [4] shows both males and females prefer faces that resemble their own. In this paper, we develop a quantitative method for measuring facial attractiveness using a combination of several factors that have been deemed significant in previous research. Many previous studies have used composite faces or faces that are altered in some other way to study the effects of symmetry and averageness on attractiveness [2,5-16]. In contrast, we use the actual faces compiled from a standard face recognition database for our analysis as the process of averaging faces for composites can diminish the appearance of at- tributes that would classify a face as more or less attractive [17]. We then determine the location of important landmarks in the face [18,19]. In all, 29 landmarks on each face as described by Shi et al. [20] are used to take physical measurements and compute the values of three factors: neoclassical canons, symmetry, and golden ratios. The faces are presented to a set of human subjects to determine their perceived attractiveness to find which factor or which combination of factors is the best predictor of attractiveness. We systematically investigate the relationship between a face's measurements and its attractiveness. The features that play the greatest role in attractiveness are identified for both genders of raters and faces. In addition, the way males and females view attractiveness in faces of the same and opposite gender is explored as there are differing accounts in the literature. Perrett et al. [12] show that males and females prefer caricatured composite faces to average composite faces in both male and female images. O'Toole et al. [17] find that females rate female faces significantly higher than they rate male faces and that the femininity of females is strongly related to attractiveness. Full details of this research can be found in reference [21]. 

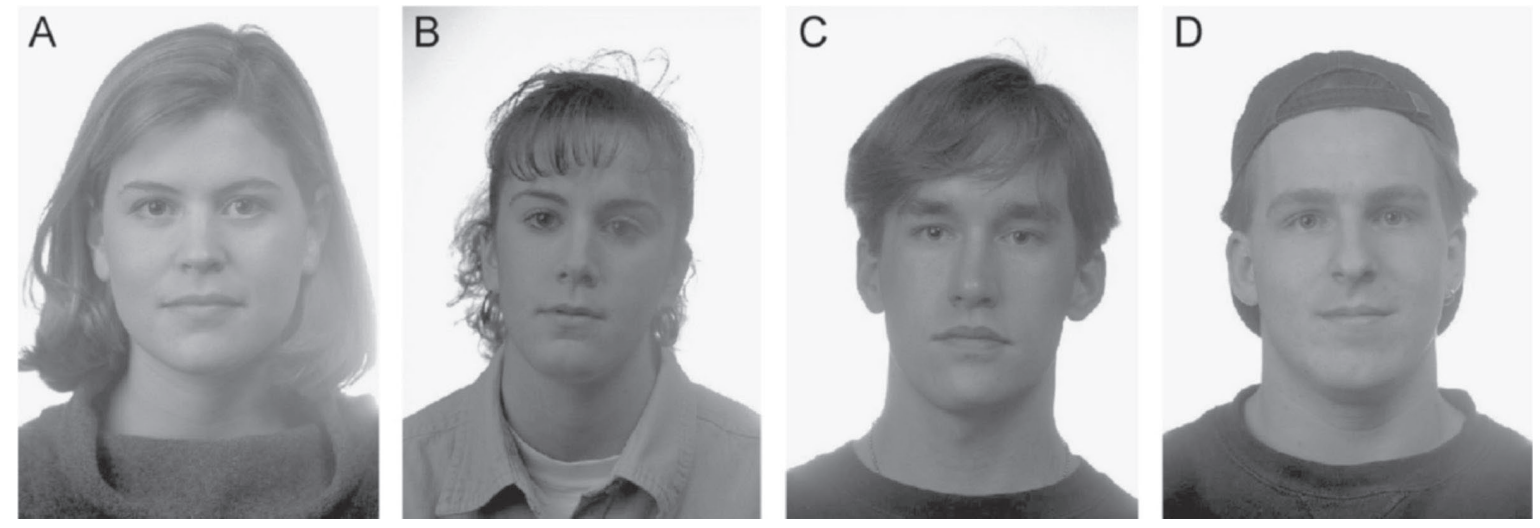

Figure 1. Sample images taken from the FERET database.
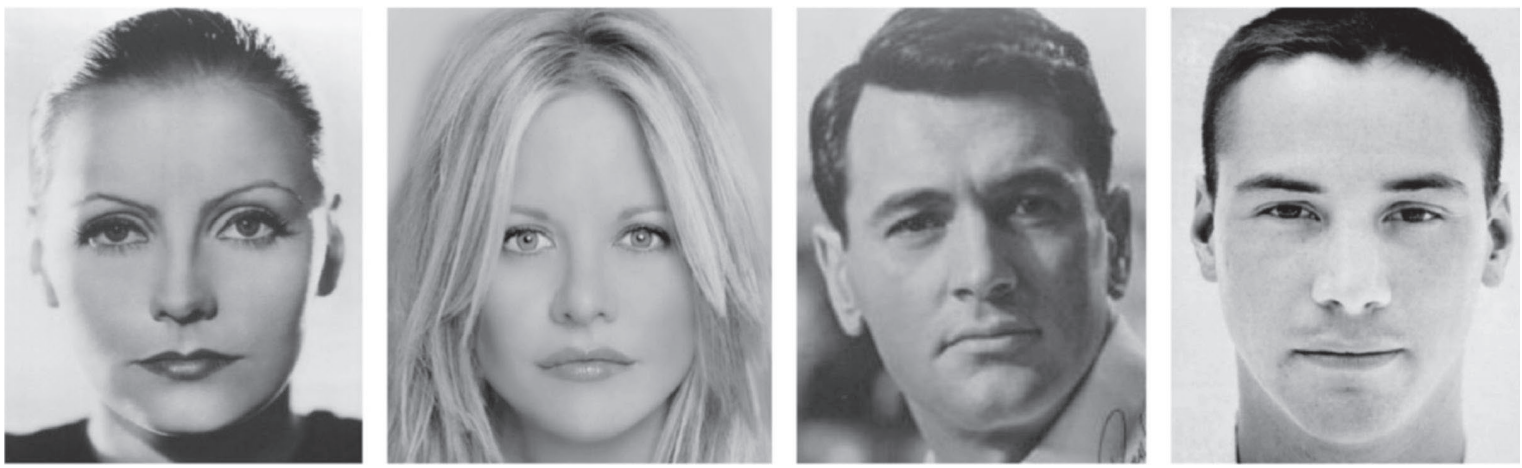

Figure 2. Sample images of faces known to be attractive. (Greta Garbo, Meg Ryan, Cary Grant, Keanu Reeves)

\section{Datasets and experimental design}

We begin with an image database containing a set of face images for the experiment and analysis. Using the image database, two datasets are compiled for the analysis. The feature dataset consists of the locations of the landmarks in the faces. The attractiveness dataset contains the attractiveness ratings given to the images by the human participants.

\subsection{The image database}

The majority of the images used in this research were taken from the Facial Recognition Technology (FERET) Database [22].

Image selection and filtering: For this research, only the images that showed full frontal views of Caucasian faces with little or no facial expression were chosen. The images were converted to gray scale to reduce the effects of skin color. The result was a set of 420 unique images with equal number of males and females (see Figure 1). In addition, the images of 32 popular movie personalities ranging from the 1930s until the present day [23] with an equal number of male and female faces were used. The motivation for including such faces, deemed more attractive than the norm, was to provide validation to our system of rating. The personalities were chosen to include only those that were considered to be attractive because the ratings given to these faces would be expected to be significantly higher than the ratings given to the faces of non-famous people. Including both recent and past personalities allowed for the possibility that not every rater would recognize all the personalities. This helped protect against higher ratings based purely on recognition of the face. Figure 2 shows some sample face images from this set.

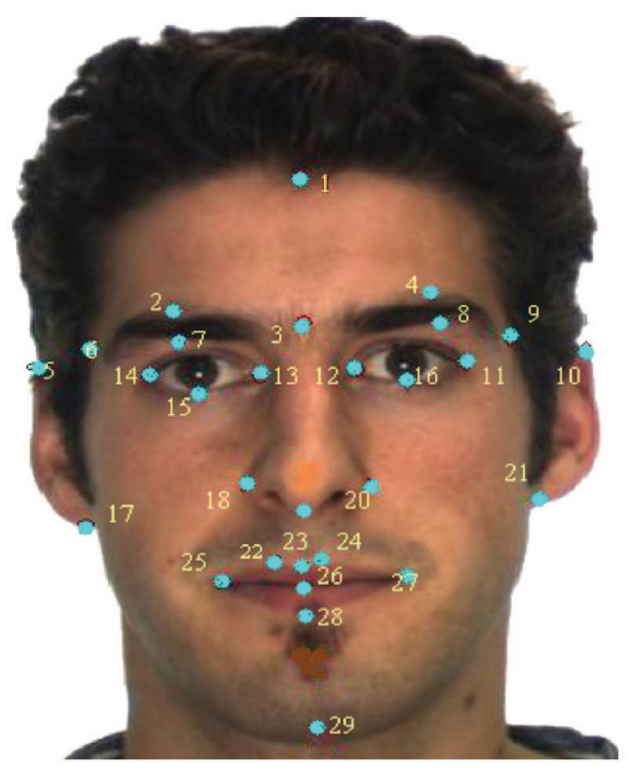

Figure 3. Feature points on an image. 


\subsection{The feature point database}

Using a customized graphical user interface, 29 important landmarks were extracted from each of the 452 images. The feature points (shown in Figure 3) were selected based on existing literature [18]. The feature point database consists of the locations of the feature points for the faces from the FERET database and the faces of famous people.

\subsection{Attractiveness scores database}

The attractiveness scores of faces in the database were compiled by asking human subjects to rate the faces using a 10-point scale. Using a partially balanced incomplete block design the 420 FERET images were split into six groups of 70 images with each group consisting of 35 males and 35 females. Each group has a total of 30 duplicate images, 15 male and 15 female duplicates, for a total of 100 images per group. Each participant was assigned to rate two of these groups. Including the duplicates provides a way to check the consistency within each rater. In addition to these 200 images, each subject rated each of the famous faces for a total of 232 faces.

Thirty-six participants (18 males and 18 females) were chosen from students and employees at the University of Nebraska-Lincoln and ranged in age from 19 to 61 years. Each participant rated each face image on a scale from 1 (least attractive) to 10 (most attractive) based on his or her opinion. In addition to the score given by the rater, we record the time taken to give the ratings. After rating the 232 images, the participant is given the option to rate him or herself using the same 10-point attractiveness scale.

\section{Computation of attractiveness predictors}

The main motivation of this research is to examine the attractiveness of a face, $\mathrm{Fi}$, as a function of its face geometry captured by a set of $\mathrm{m}$ landmarks. Thus:

$$
F_{i}=\left\{f_{i 1}, f_{i 2}, \ldots, f_{i m}\right\},
$$

where each feature point, $f_{i j}=\left(x_{i j}, y_{i j}\right), 1 \leq i \leq n, 1 \leq j \leq m$, is represented by its two-dimensional spatial coordinates in the face. The goal is to determine a function A that maps a face to an attractiveness score.

$$
A\left(F_{i}\right) \rightarrow[1,10]
$$

To compute the attractiveness, we use three predictors that have been proposed in literature: neoclassical canons, face symmetry, and golden ratios.

\subsection{Neoclassical Canons}

Neoclassical canons have been proposed by artists dating back to the renaissance period as guides to drawing beautiful faces [24]. The basic premise is that portions of an attractive face should follow certain defined ratios. Farkas et al. [24] summarize these principles in nine neoclassical
Table 1. Description of neoclassical canons (formula number given by reference [24])

\begin{tabular}{cl}
\hline Formula number & Description \\
\hline 2 & Forehead height $=$ nose length $=$ lower face height \\
4 & Nose length = ear length \\
5 & Interocular distance $=$ nose width \\
6 & Interocular distance $=$ right or left eye fissure width \\
7 & Mouth width $=1.5 \times$ nose width \\
8 & Face width $=4 \times$ nose width \\
\hline
\end{tabular}

canons and their variations. Only six of these (Table 1) can be tested using our 29 landmarks.

As shown in Table 1, some canons use two measurements (e.g. Formulas 4 and 8) while others use three (e.g. Formulas 2 and 6). To consistently measure compliance with the canons (i.e. equality to proposed ratios) with different number of features, we use the coefficient of variation (ratio of the standard deviation of the distances to the mean of the distances). Using the coefficient of variation allows us to incorporate all three distances into one value. A value of zero for the coefficient of variation says there is no variation in the distances (they are equal). For non-zero values, the larger the value, the more the face differs from the canon.

\subsection{Symmetry}

Symmetry for a face is considered to be an important factor for attractiveness [2]. Symmetry has been defined in many different ways $[2,5,10,13,14,16,25-29]$; however, many consider only the symmetry about a vertical axis. The axis of symmetry in this study is defined by fitting the least squares regression line through the seven points measured along the middle of the face (Points 1, 3, 19, 23, 26, 28, 29 shown in Figure 3). We use the following feature pairs (left and right) for the analysis of symmetry:

- eyebrows (Points 2 and 4; Points 7 and 8);

- eyes (Points 11 and 14; Points 12 and 13; Points 15 and 16);

- nose (Points 18 and 20);

- ears (Points 5 and 10; Points 17 and 21);

- lips (Points 22 and 24; Points 25 and 27);

- face (Points 6 and 9) .

To compute the symmetry of a face, we first compute the symmetry of the individual features. Literature in sexual size dimorphism (SSD) [30] has identified many formulas to compare the measurements for males and females. SSD uses differences or ratios of features to help in determining the degree of difference between male and female measurements. Some of the same indices can be used to determine the degree of difference between the left and right sides of a face. We refer to these as facial symmetry measures (FSM); they are functions of the perpendicular distance $(d)$ from a given feature point to the line of symme- 
Table 2. Golden ratios obtained from references $[31,32]$

\begin{tabular}{llll}
\hline Ratio number & Numerator points & Denominator points & Description \\
\hline 1 & $\mathrm{y} 10-\mathrm{y} 21$ & $\mathrm{x} 12-\mathrm{x} 13$ & Ear length t interocular distance \\
2 & $\mathrm{y} 10-\mathrm{y} 21$ & $\mathrm{x} 18-\mathrm{x} 20$ & Ear length to nose width \\
3 & $\mathrm{x} 15-\mathrm{x} 16$ & $\mathrm{x} 12-\mathrm{x} 13$ & Mideye distance to interocular distance \\
4 & $\mathrm{x} 15-\mathrm{x} 16$ & $\mathrm{x} 18-\mathrm{x} 20$ & Mideye distance to nose width \\
5 & $\mathrm{x} 25-\mathrm{x} 27$ & $\mathrm{x} 12-\mathrm{x} 13$ & Mouth width to interocular distance \\
6 & $\mathrm{y} 23-\mathrm{y} 29$ & $\mathrm{x} 12-\mathrm{x} 13$ & Lips-chin distance to interocular distance \\
7 & $\mathrm{y} 23-\mathrm{y} 29$ & $\mathrm{x} 18-\mathrm{x} 20$ & Interocular distance to eye fissure width \\
8 & $\mathrm{x} 12-\mathrm{x} 13$ & $\mathrm{y} 12-\mathrm{x} 11$ & Interocular distance to lip height \\
9 & $\mathrm{x} 12-\mathrm{x} 13$ & $\mathrm{x} 12-\mathrm{x} 11$ & Nose width to eye fissure width \\
10 & $\mathrm{x} 18-\mathrm{x} 20$ & $\mathrm{y} 23-\mathrm{y} 28$ & Nose width to lip height \\
11 & $\mathrm{x} 18-\mathrm{x} 20$ & $\mathrm{y} 19-\mathrm{y} 26$ & Eye fissure width to nose-mouth distance \\
12 & $\mathrm{x} 12-\mathrm{x} 11$ & $\mathrm{y} 19-\mathrm{y} 26$ & Lip height to nose-mouth distance \\
13 & $\mathrm{y} 23-\mathrm{y} 28$ & $\mathrm{x} 17-\mathrm{x} 21$ & Length of face to width of face \\
14 & $\mathrm{y} 1-\mathrm{y} 29$ & $\mathrm{y} 26-\mathrm{y} 29$ & Nose-chin distance to lip-chin distance \\
15 & $\mathrm{y} 19-\mathrm{y} 29$ & $\mathrm{y} 19-\mathrm{y} 26$ & Nose width to nose-mouth distance \\
16 & $\mathrm{x} 18-\mathrm{x} 20$ & $\mathrm{x} 18-\mathrm{x} 20$ & Mouth width to nose width \\
17 & $\mathrm{x} 25-\mathrm{x} 27$ & &
\end{tabular}

try. Four different functions to compute the face symmetry measure are shown below.

$$
\begin{aligned}
& \text { Difference: } F S M_{\text {Diff }}(d)=d_{L}-d_{R} \\
& \text { Ratio: } F S M_{\text {Ratio }}(d)=d_{L} \div d_{R} \\
& \text { LN(Ratio): } F S M_{\text {LNRatio }}(d)=\ln \left(d_{L} \div d_{R)}\right. \\
& \text { Adjusted Difference: } F S M_{\text {AdjDiff }}(d)=\left[\frac{d_{L}-d_{R}}{\left(d_{L}+d_{R}\right) / 2}\right]
\end{aligned}
$$

For the difference, adjusted difference, and natural log of the ratio, a value of zero implies symmetry; the greater the absolute value the less symmetric the face. For the ratio, a value of 1 indicates symmetry.

The above measures are useful in measuring degree of symmetry when the face is vertical. However, when the face is tilted or rotated about the vertical axis, this measure is not accurate. We hypothesize that incorporating both angle (a) and distance into the measure of symmetry will result in better predictions of attractiveness scores than using distances alone. The points are considered symmetric if $a=0$ and $d_{L}=d_{R}$. The horizontal distances and angles are used to compute the symmetry of a face since together they measure both the horizontal and vertical symmetries in the face. See reference [21] for more details.

\subsection{Golden Ratios}

While there is no published study that shows correlation between attractiveness and proportions in face measurements that approach the golden ratio, such relationships have been reported in popular literature [31,32]. According to these reports, faces that have features with ratios close to the golden ratio are thought to be aesthetically pleasing. With the points available in this study, there are 17 ratios used to explore their relationship to attractiveness. Table 2 describes these ratios and identifies the points used for each, where $x$ or $y$ refers to the $x$-coordinate or $y$-coordinate of the points and the numbers indicate which points from Figure 3 were used in calculating the ratio.

\section{Analyses and results}

We begin with the examination of a set of general questions about the attractiveness of human faces, including the variability of raters and effect of self-perceived attractiveness. Then the roles of the three predictor variables, neoclassical canons, symmetry, and golden ratio, in the attractiveness of a face are examined. All analyses use the statistical analysis software (SAS) [33].

\subsection{General questions about attractiveness}

Do males and females rate faces differently? It has been reported in literature that males and females generally agree on attractiveness [12,34]. An analysis of variance was conducted with the average rating $(A R)$ of the image by each participant as the dependent variable. The ratings of duplicate images were averaged for each rater. The following statistical model was used:

$$
\begin{gathered}
A R_{i j k l}=S_{i}+P(S)_{i j}+G_{k}+I(G)_{k l}+(S * G)_{i k}+e_{i j k l^{\prime}} \\
i=1,2, j=1, \ldots, 18, k=1,2, l=1, \ldots, 116,
\end{gathered}
$$

where $S$ is the effect due to gender of the participant, $P(S)$ is the random effect due to participant, $G$ is the effect of image gender, $I(G)$ is the random effect due to image, $S$ * $G$ is the interaction effect due to the gender of the participant and gender of the image, and $e$ is residual error. There was a slight difference in how men and women rated faces overall $(p=0.0571)$, with males rating faces higher than females. Female faces are rated significantly higher than male faces $(p=0.0004)$ by both male and female raters. 
When the data were separated into famous and nonfamous faces, the results suggest that males and females view attractiveness the same when looking at known attractive faces, but do not agree on attractiveness of nonfamous faces. Famous females are not rated significantly higher than their male counterparts while non-famous female faces are.

Do the male and female raters exhibit the same variability when rating faces? The dataset for this analysis consisted only of those faces that were rated twice by the same rater resulting in 120 ratings by each participant. The variance for each rater and each face gender was computed as the variance in ratings of the same face compounded over all 30 sets of duplicate faces given to each rater. Thus, we have two variances per subject (72 variances in all), one for male faces and one for female faces. The variances were found to follow a lognormal distribution, so the GLIMMIX procedure in SAS was used [35].

Results show that the variability with which females and males rated images did not differ depending on the gender of the face. Although the difference is not significant $(p=0.1658)$, females $\left(\sigma^{2}{ }_{M}=0.8318\right)$ had somewhat higher variability in their ratings than males $\left(\sigma^{2}{ }_{M}=0.5854\right)$.

Does the self-perception of attractiveness affect ratings? A positive relationship was found between the self ratings of participants and their average rating of others (intercept $\left.=2.898, b=0.38, p=0.0041, R^{2}=0.3437\right)$. As an individual's perception of his or her own attractiveness increases, so does his or her average rating of others. Separate analysis for males and females yielded similar results. Both had positive linear relationships, although the relationship was not significant for females (intercept $=3.1484, b=0.30, p=$ $0.156, R^{2}=0.234$ ). The linear relationship between self rating and rating of others for male participants was stronger (intercept $=3.2116, b=0.359, p=0.049, R^{2}=0.334$ ).

A plot of self ratings leads us to hypothesize that males rate themselves higher than females [21]. Males rated themselves at an average of 6.833 while females rated themselves at an average of 6.0; this difference is not significant $\left(t_{20}=-1.46, p=0.1605\right)$.

Is attractiveness related to speed of rating? There is a significant relationship between the time it took to rate a face and the rating given to it. However, this relationship is dependent on the gender of the rater $(p=0.0016)$. For each additional second a female spent rating an image, the rating decreased by 0.0135 points, although it is not significant $(p=0.3194)$. For each additional second males spent looking at an image, the rating they gave increased by an average of 0.0408 points $(p=0.0072)$. These trends did not depend on the gender of the face.

\subsection{Relationship between neoclassical canons and face attractiveness}

Of the six neoclassical canons described in Section 3.1, five had a significant relationship with attractiveness. Only Formula 7 (mouth width $=1.5 \times$ nose width) showed no relationship $(p=0.1412)$. If the canons are a true predictor of attractiveness, the scores would decrease as the coeffi- cient of variation increases. This was true for all but one of the five significant canons. For Formula 5 (interocular distance $=$ nose width), the attractiveness scores decreased as the coefficient of variation increased for male images, but the scores actually increased for female images $(p=0.0028)$. This suggests that female faces are viewed as more attractive when they have smaller noses and/or a larger distance between their eyes than proposed by the canon. For Formulas 2, 4, 6, and 8, the attractiveness scores decreased significantly as the proportions of the face deviated from the proportions defined by the canons $(p=0.0009, p=0.0014, p$ $<0.0001$, and $p=0.0064$, respectively).

\subsection{Relationship between symmetry and face attractiveness}

In Section 3.2, four measures to compute the symmetry in a face were presented. The first task was to determine which of the four measures had the strongest relationship with attractiveness. We also wanted to determine if adding angle symmetry significantly increased the ability to predict attractiveness score. Finally, the pair(s) of points that play significant roles in the attractiveness of a face were identified.

Face symmetry measures. Our analysis of the four face symmetry measures shows that the difference symmetry measure, which measures the difference in distances from the symmetric points to the line of symmetry, has the strongest relationship with attractiveness. When the angle symmetry measures are added to the difference symmetry measures and its relationship to attractiveness was evaluated, there was a slight increase in the $R^{2}$ values. However, the increase was very small and therefore it was not included for the rest of the analysis.

Significant feature points. To determine the contribution of the symmetry pairs toward attractiveness of a face, a stepwise regression analysis was used to reduce the number of variables in the model. The analysis show that both male and female raters find the symmetry of the nose (Points 18 and 20) and mouth (Points 25 and 27) as an important part of attractiveness when viewing male and female images $(p=0.0025, p=0.0604)$. The symmetry of the upper tips of the lips (Points 22 and 24) is also important for both genders of raters and images.

\subsection{Relationship between golden ratios and face attractiveness}

Of the 17 ratios described in Section 3.3 only 6 (ratios 2, $5,6,7,14$, and 17) are predictors of attractiveness.

- The ratings given by females decrease by a significantly larger amount than those given by males $(p=0.0040)$ as ratio 2 (ear length to nose width) deviates from the golden ratio. The same is true for the ratio of lip to chin distance to nose width (ratio $7, p=0.0151$ ) and mouth width to nose width (ratio 17, $p=0.0030$ ).

- Both males and females rate images higher as ratios 5 and 6 (mouth width to interocular distance, $p=0.0020$; lip to chin distance to interocular distance, $p<0.0001$, re- 
spectively) approach the golden ratio. This trend is the same for both genders of images.

- As the ratio of the length of the face to the width of the face (ratio 14) gets closer to the golden ratio, both male and female images are viewed as more attractive $(p=$ 0.0077). However, female images that deviate from the golden ratio have significantly lower ratings by female raters than by male raters. Male images that deviate from the golden ratio have the same decrease in attractiveness score when rated by males or females.

\subsection{Combining multiple measures to predict attractiveness}

Using the neoclassical canons, difference symmetry measures, and golden ratios found to have a significant relationship with attractiveness, we developed a model for predicting attractiveness. A complete model with 78 variables ( 6 canons, 55 symmetry, 17 golden ratios) yielded $R^{2}=0.2433$. Using stepwise regression, an optimized model was developed containing only 16 predictor variables with $R^{2}=0.1923$. Since we had observed that males and females view the attractiveness of certain features differently in faces of the same and opposite gender, we developed separate parsimonious models for each gender combination. By separating into four different models, each was able to predict attractiveness better than the optimized model using all 16 variables. In addition, we were able to eliminate up to half of the 16 variables without incurring much reduction in the $R^{2}$ values. Table 3 summarizes the results.

While each of the four models is slightly different, results show that Canon 6 (interocular distance $=$ right or left eye fissure width), symmetry pair 22-24 (tips of upper lip), and golden ratios 5 and 7 (ratio of lip to chin distance and width of the nose) are universally important in attractiveness of faces (Table 4).

Female raters preferred the ratio of lip to chin distance with interocular distance (ratio 6) to be less than the golden ratio no matter the gender of the face. This suggests that female raters view a smaller chin and/or larger distance between the eyes as more attractive.

Male raters viewed the equality of the ear length and nose length (canon 4) as attractive regardless of the face gender. They also gave higher ratings when the nose width was not quite equal to one-fourth of the face width (canon 8 ). From this information it seems male raters prefer a more slender face and/or a smaller nose.

Female faces were rated higher when the mouth width to interocular distance (ratio 5) and ratio of the length to width of the face (ratio 14) were slightly less than the golden ratio. They were rated higher when the ratio of the mouth to the nose (ratio 17) was proportional to the golden ratio. Ratings of female faces were higher when the upper tips of the lips (Points 22 and 24) were slightly asymmetric which could support the claim that fuller lips are more attractive in females [2]. Overall, larger distances between the eyes and/or smaller mouth width along with face length to width in proportion less than the golden ratio are seen as attractive in female faces.
For male faces, symmetry of the upper tips of the lips (Points 22 and 24) and symmetry of the nose (Points 18 and 20) is viewed as attractive. The face being divided into equal vertical thirds (canon 2) is an attractive trait in men. The attractiveness scores are higher when the ratio of the mouth to the interocular distance (ratio 5) is proportional to the golden ratio and the ratio of lip to chin distance with interocular distance (ratio 6) is less than the golden ratio. The latter of the two ratios was also viewed as important to attractiveness by female raters.

Even though the $R^{2}$ values did not seem very high, we were able to explain between one-fifth and one-quarter of the variation in attractiveness ratings using various neoclassical canons, symmetry measures, and golden ratios. This is quite significant given the large amount of variation in the attractiveness scores and the fact that only face geometry is used. The models used produce predicted values that are generally close to the actual attractiveness scores which is evidenced by the small residual values for any rater gender and face gender combination. The studentized residuals were all between -1.48 and 1.45 , well inside the usually acceptable range of \pm 2 , verifying that our models for predicting attractiveness work rather well. Table 5 shows the actual and predicted attractiveness scores for the faces in Figures 1 and 2.

Table 3. Summary of each model after stepwise variable selection

\begin{tabular}{lllc}
\hline Rater/face & $\begin{array}{l}R^{2} \\
\text { (optimized) }\end{array}$ & $\begin{array}{l}R^{2} \\
\text { (reduced) }\end{array}$ & $\begin{array}{l}\text { No. variables in } \\
\text { reduced model }\end{array}$ \\
\hline Female/female & 0.2378 & 0.2335 & 8 \\
Female/male & 0.2162 & 0.2097 & 8 \\
Male/female & 0.2106 & 0.2088 & 11 \\
Male/male & 0.2053 & 0.2013 & 10 \\
\hline
\end{tabular}

Table 4. Canon formulas, symmetry pairs, and golden ratios in the final models

\begin{tabular}{llll}
\hline \multicolumn{2}{l}{ Variables in final models } & & \\
\hline Rater/face & \multicolumn{1}{l}{ Canon formulas } & Symmetry pairs & \multicolumn{1}{c}{ Ratio nos. } \\
\hline Female/female & 6,8 & $22-24$ & $5,6,7,14,17$ \\
Female/male & 2,6 & $7-8,18-20,22-24$ & $5,6,7$ \\
Male/female & $2,4,5,6,8$ & $22-24$ & $2,5,7,14,17$ \\
Male/male & $2,4,6,8$ & $18-20,22-24,25-27$ & $5,6,7$
\end{tabular}

Table 5. Observed and predicted attractiveness scores

\begin{tabular}{lll}
\hline Face & Actual score & Predicted score \\
\hline A & 6.0833 & 5.9379 \\
B & 5.2083 & 5.2798 \\
C & 6.0000 & 5.8239 \\
D & 5.5833 & 5.6342 \\
Greta Garbo & 7.0278 & 7.0005 \\
Meg Ryan & 8.4167 & 8.0032 \\
Rock Hudson & 7.8333 & 6.1887 \\
Keanu Reeves & 7.3333 & 6.8778 \\
\hline
\end{tabular}


Except for the case of Rock Hudson, the predicted scores are close to the actual score. The face of Rock Hudson as shown in Figure 2 is tilted and somewhat rotated which is a possible explanation as to why the model underestimated the attractiveness.

\section{Summary and future work}

The goal of this study is to determine a predictive model for attractiveness based on neoclassical canons, symmetry, and golden ratios. In contrast with much of the previous work, our study used landmarks and geometry based means for computing symmetry and had people rate actual faces instead of composite or altered faces. We also include both faces of the general population and known attractive faces. In addition, both the gender of the rater and the face are identified as to compare the ratings given to the same and opposite genders. While men and women do generally agree on overall attractiveness, male raters tend to give higher scores than females. In addition, we find that male and female raters use somewhat different criteria for determining the attractiveness of a face. Female faces were rated higher by both male and female raters which supports feminine traits being viewed as attractive [2,17,36,37], but goes against the idea that ratings reflect a sexual attractiveness toward faces of the opposite gender [38]. Our study on attractiveness is centered around the geometry of the face using a set of landmarks. This facilitates understanding roles of individual symmetric feature pairs and proportions in the attractiveness of a face. Our study is consistent with reference [2] in concluding that smaller chins in females are more attractive. We also find that smaller noses, a larger distance between the eyes, and smaller widths of the mouth are desirable traits for females.

Symmetry does not play as important a role in attractiveness as the proportions defined by the neoclassical canons and golden ratios. This is demonstrated by the small proportion of symmetry predictor variables, as compared to the proportions of canons and golden ratios that were selected by the stepwise procedures to be included in the final models. Only 3 of the 11 difference symmetry measures were in any of the four reduced models, while 5 of 6 canons and 6 of 17 golden ratios were included in at least one of the four models.

While the results presented in this paper provide strong insights into the role that different aspects of face geometry play in attractiveness, this research can be extended in many different directions. Attractiveness is a complex aspect of a face and involves many other issues, for example, references [2,12] and others have studied the effects of averageness on the attractiveness of faces. We are interested in exploring this issue using a landmark-based approach. A secondary motive for including the faces of famous people was to see if the perception of attractiveness changes over time. Our famous faces included two male and two female faces from each of the past eight decades which would allow us to determine if a relationship with attractiveness exists due to the age of the rater and the time period during which the person was famous.

\section{References}

[1] J. Armstrong, The Secret Power of Beauty: Why Happiness is in the Eye of the Beholder, Allen Lane, London, 2004.

[2] G. Rhodes, The evolutionary psychology of facial beauty, Annu. Rev. Psychol. 57 (2006) 199-226.

[3] A.C. Little, D.M. Burt, I.S. Penton-Voak, D.I. Perrett, Self-perceived attractiveness influences human female preferences for sexual dimorphism and symmetry in male faces, Proc. R. Soc. Lond. Ser. B. Biol. Sci. 268 (2000) 39-44.

[4] L.M. DeBruine, Facial resemblance increases the attractiveness of same-sex faces more than other sex faces, Proc. R. Soc. Lond. Ser. B. Biol. Sci. 271 (2004) 2,085-2,090.

[5] R. Kowner, Facial asymmetry and attractiveness judgement in developmental perspective, J. Exp. Psychol. Hum. Percept. Perform. 22 (1996) 662-675.

[6] J.H. Langlois, L.A. Roggman, Attractive faces are only average, Psychol. Sci. 1 (1990) 115-121.

[7] J.H. Langlois, L.A. Roggman, L. Musselman, What is average and what is not average about attractive faces?, Psychol. Sci. 5 (1994) 214-220.

[8] A.C. Little, P.J.B. Hancock, The role of masculinity and distinctiveness in judgments of human male facial attractiveness, $\mathrm{Br}$. J. Psychol. 93 (2002) 451-464.

[9] A.J. O'Toole, T. Price, T. Vetter, J.C. Bartlett, V. Blanz, 3D shape and 2D surface textures of human faces: the role of "averages" in attractiveness and age, Image Vis. Comput. 18 (1999) 9-19.

[10] D.I. Perrett, D.M. Burt, I.S. Penton-Voak, K.J. Lee, D.A. Rowland, R. Edwards, Symmetry and human facial attractiveness, Evol. Hum. Behav. 20 (1999) 295-307.

[11] D.I. Perrett, K.J. Lee, I.S. Penton-Voak, D. Rowland, S. Yoshikawa, D.M. Burt, S.P. Henzill, D.L. Castles, S. Akamatsu, Effects of sexual dimorphism on facial attractiveness, Nature 394 (1998) 884-887.

[12] D.I. Perrett, K.A. May, S. Yoshikawa, Facial shape and judgements of female attractiveness, Nature 368 (1994) 239-242.

[13] G. Rhodes, F. Proffitt, J.M. Grady, A. Sumich, Facial symmetry and the perception of beauty, Psychol. Bull. Rev. 5 (1998) 659-669.

[14] G. Rhodes, A. Sumich, G. Byatt, Are average facial configurations attractive only because of their symmetry?, Psychol. Sci. 10 (1999) 52-58.

[15] G. Rhodes, T. Tremewan, Averageness, exaggeration, and facial attractiveness, Psychol. Sci. 7 (1996) 105-110.

[16] J.P. Swaddle, I.C. Cuthill, Asymmetry and human facial attractiveness - symmetry may not always be beautiful, Proc. $R$. Soc. Lond. Ser. B. Biol. Sci. 261 (1995) 111-116.

[17] A.J. O'Toole, K.A. Deffenbacher, D. Valentin, K. McKee, D. Huff, H. Abdi, The perception of face gender: The role of stimulus structure in recognition and classification, Mem. Cognit. 25 (1997).

[18] L.G. Farkas, Anthropometry of the Head and Face, second ed., Raven Press, New York, 1994.

[19] L.G. Farkas, I.R. Munro, Anthropometric Facial Proportions in Medicine, Charles C. Thomas, Illinois, 1987.

[20] J. Shi, A. Samal, D. Marx, How effective are landmarks and their geometry for face recognition?, Comput. Vision Image Understanding 102 (2006) 117-133.

[21] K. Schmid, D. Marx, A. Samal, Computation of a face attractiveness index based on neoclassical canons, symmetry, and golden ratios, Department of Statistics Technical Reports, University of Nebraska, 2006. Available on the World Wide Web 
at http://statistics.unl.edu/Resources/Techrep/Attractiveness_Paper_Fullvers.pdf.

[22] P.J. Phillips, H. Moon, S.A. Rizvi, P.J. Rauss, The FERET evaluation methodology for face-recognition algorithms, IEEE Trans. Patt. Anal. Mach. Intell. 22 (2000) 1,090-1,104.

[23] Movie Actor Index. Available on the World Wide Web at http:/ / www.movieactors.com, 2006 (last accessed 12.20.06).

[24] L.G. Farkas, T.A. Hreczko, J.C. Kolar, I.R. Munro, Vertical and horizontal proportions of the face in young adult North American Caucasians: revision of neoclassical canons, Plast. Reconstr. Surg. 75 (1985) 328-337.

[25] K. Grammer, R. Thornhill, Human (Homo sapiens) facial attractiveness and sexual selection: the role of symmetry and averageness, J. Comp. Psychol. 108 (1994) 233-242.

[26] A.C. Little, B.C. Jones, Attraction independent of detection suggests special mechanisms for symmetry preferences in human face perception, Proc. R. Soc. Lond. Ser. B. Biol. Sci. 273 (2006) 3,093-3,099.

[27] I.S. Penton-Voak, B.C. Jones, A.C. Little, S. Baker, B. Tiddeman, D.M. Burt, D.I. Perrett, Symmetry, sexual dimorphism in facial proportions and male facial attractiveness, Proc. $R$. Soc. Lond. Ser. B. Biol. Sci. 268 (2001) 1,617-1,623.

[28] C.A. Samuels, G. Butterworth, T. Roberts, L. Graupner, G. Hole, Facial aesthetics - babies prefer attractiveness to symmetry, Perception 23 (1994) 823-831.

[29] J.E. Scheib, S.W. Gangestad, R. Thornhill, Facial attractiveness, symmetry and cues of good genes, Proc. R. Soc. Lond. Ser. B. Biol. Sci. 266 (1999) 1,913-1,917.

[30] R.J. Smith, Statistics of sexual size dimorphism, J. Hum. Evol. 36 (1999) 423-459.

[31] G. Meisner, The human face. Available on the World Wide Web at http:/ / goldennumber.net/face, 2006 (last accessed 12.9.06).

[32] D.L. Narain, The perfect face. Available on the World Wide Web at http://cuip.uchicago.edu/ dlnarain/golden/activity8.htm, 2003 (last accessed 12.9.06).

[33] SAS Institute, Online Document, Version 9, SAS Institute Inc., Cary, NC, 2003.

[34] J.H. Langlois, L. Kalakanis, A.J. Rubenstein, A. Larson, M. Hallam, M. Smoot, Maxims or myths of beauty? A meta-analytic and theoretical review, Psychol. Bull. 126 (2000) 390-423.

[35] O. Schabenberger, Introducing the GLIMMIX procedure for generalized linear mixed models, Paper 196-30, SUGI 30, SAS Institute Inc., Cary, NC, 2005.

[36] M.R. Cunningham, Measuring the physical in physical attractiveness: quasi-experiments on the sociobiology of female facial beauty, J. Pers. Soc. Psychol. 50 (1986) 925-935.

[37] M.R. Cunningham, A.R. Roberts, A.P. Barbee, P.B. Druen, C.$\mathrm{H}$. $\mathrm{Wu}$, "Their ideas of beauty are, on the whole, the same as ours": consistency and variability in the crosscultural perception of female physical attractiveness, J. Pers. Soc. Psychol. 68 (1995) 261-279.

[38] M.R. Cunningham, A.P. Barbee, C.L. Pike, What do women want? Facial metric assessment of multiple motives in the perception of male facial physical attractiveness, J. Pers. Soc. Psychol. 59 (1990) 61-72.

\section{About the Authors}

Kendra Schmid obtained a M.S. (2004) and Ph.D. in Statistics (2007) from the University of Nebraska-Lincoln. Besides her interests in pattern and shape analysis and statistics education, her research has involved statistical computing and nonlinear models. She is an Assistant Professor of Biostatistics at the University of Nebraska Medical Center.

David Marx is a Professor of Statistics at the University of Nebraska-Lincoln. He obtained his B.S. in Chemistry from the College of Wooster in Ohio, M.S. and Ph.D. in Statistics from the University of Missouri and the University of Kentucky, respectively. His research interests include spatial statistics, geostatistics, and statistical computing.

Ashok Samal received his B.Tech. in Computer Science from Indian Institute of Technology and Ph.D. from the University of Utah. He is an Associate Professor with the Department of Computer Science and Engineering at the University of Nebraska-Lincoln. He has published over 70 papers in image understanding, document analysis, and geospatial computing. 